\title{
Políticas visuales en el movimiento global por Ayotzinapa
}

\section{Visual policies in the global mouvment for Ayotzinapa}

\author{
TIPO DE TRABAJO: Comunicación.
}

PALABRAS CLAVE

Imagen, Agencia, Políticas Visuals, Ayotzinapa, Movimientos sociales.

KEY WORDS

Image, Agency, Visual Policies, Ayotzinapa, Social Movements.

RESUMEN

La desaparición de 43 estudiantes el 26 de septiembre de 2014 en el estado de Guerrero, México generó una crisis política que condujo a la crisis del régimen el 1 de julio del 2018. La ponencia propone una reflexión sobre las formas en las que, de acuerdo con Remedios Zafra (Ojos y Capital, 2015), la producción de imágenes que ha acompañado la movilización que demanda verdad y justicia en el caso de la desaparición de los estudiantes modificó la dialéctica entre el yo y el nosotros que orienta las relaciones sociales y contribuyó a ahondar la crisis política antes referida. A través del análisis de la de la agencia (Gell, Arte y Agencia. Una teoría antropológica, 2004) de una selección de imágenes se mostrará el potencial de los artistas para activar políticas visuales basada en la ética y la responsabilidad con el otro.

\section{ABSTRACT}

The disappearance of 43 students in the state of Guerrero, Mexico on 26 September 2014 generated a political crisis that led to of the fall of the regime on July 1, 2018. Based on the work of Remedios Zafra (Ojos y Capital, 2015), the paper reflects on the ways in which the production of images that have accompanied this social movement modified the dialectic between the "I" and the "us" that guides social relations and contributed to deepening the aforementioned political crisis. Through the analysis of the agency ( Through the analysis of the agency (Gell, Art an Agency, an Anthopological Theory, 2004) of a selection of images the paper shows the potential of artists to activate visual policies based on notions of ethics and responsibility with the Other.

\section{INTRODUCCIÓN}

En el año 2014, la desaparición de 43 estudiantes de la Escuela Normal Rural Raúl Isidro Burgos de Ayotzinapa y el asesinato de seis personas más en Iguala, Guerrero, México ${ }^{1}$, cimbraron al país entero dando origen a una movilización de dolor y pérdida ${ }^{2}$ que muy pronto alcanzaría un nivel global. A partir de la teoría del nexo social del arte de Alfred Gell analizaré tres imágenes que contienen iconos ahora emblemáticos de esa movilización: la frase "Fue el Estado", los rostros de los estudaitnes y el numeral 43.

\footnotetext{
${ }^{1}$ En la noche del 26 al 27 de septiembre del 2014 la policía municipal de Iguala, Guerrero, atacó con armas de fuego a un centenar de estudiantes de la Escuela Normal Rural de Ayotzinapa. La policía mató a seis personas, hirió de gravedad a cinco más en plena vía pública y detuvo a 43 estudiantes normalistas sin dejar rastro judicial de su detención. Para un recuento de los hechos véase Illades (2015).

${ }^{2}$ Erick Galán Castro señala que la singularidad de estos movimientos sociales es que no representan intereses de reivindicaciones de clase o de derechos laborales, o el reconocimiento al respeto a los derechos de minorías étnicas o de género, sino que conforman redes de apoyo a víctimas de un evento traumático que ha generado un daño físico a ellos mismos o a terceros, y "que buscan una reparación del agravio a través de medios legales, del reconocimiento de la responsabilidad por parte de un adversario, del cese de actividades que se asumen como causa de los casos traumáticos, y del uso de la memoria y otros mecanismos emotivos y simbólicos que dan cuenta de la dimensión del problema" (Galán Castro 2017, p. 20). Entre ellos se cuentan las Madres y Abuelas de la Plaza de Mayo, en Argentina, la Agrupación de Familiares de Detenidos y Desaparecidos de Chile, Madres y Familiares de Uruguayos Detenidos Desaparecidos, entre muchos otros, y, en México, grupos como el Comité Eureka e H.I.J.O.S.
} 


\section{METODOLOGÍA}

Alfred Gell sostiene que las imágenes y los prototipos que aquellas registran son artefactos que dan cuenta de la capacidad de agencia de las producciones artísticas en el espacio público. (2004, p. 51) Estos artefactos actúan como agentes de interacciones sociales humanas que generan nuevas producciones precisamente en la interacción social, que es donde tiene lugar la convergencia de los horizontes de la voluntad y la intencionalidad de los autores con los de la sociedad. Por otra, parte, estos artefactos son índices de agencia, tanto de sus creadores como de las personas que los utilizan (p. 47) de tal suerte que, en el caso de los aquí analizados visibilizan la forma en la cual los artistas y miembros de la sociedad han contribuido a la emergencia de una política visual basada en el reconocimiento del otro que desempeñó un papel importante en la crisis que conduciría al cambio de régimen el 1 de julio de 2018. En ese sentido, esas imágenes se ubican en las antípodas de aquellas gestionadas por los ojos del capital que, como ha argumentado Remedios Zafra (2015), nos impiden ver dónde estamos y quiénes somos (p. 20). Por el contrario, en su diversificación y multiplicación, las creadas y recreadas en el movimiento global por Ayotzinapa configuran una política visual basada en la responsabilidad hacia los otros (Levinas, 1991) y en el reconocimiento de su importancia la constitución de las identidades. (Bajtin, 2000).

\section{DESARROLLO}

\section{1. "Fue el Estado"}

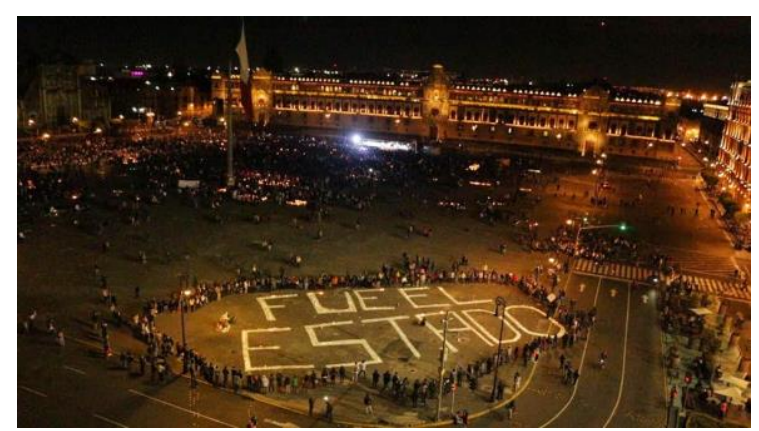

Figura 1. Fotografía de @Lalo777.Fuente: Reexiste, Publicada el 22 de octubre de 2014. Recuerpada de http://rexiste.org/post/107326632417/pintamonumental-fue-el-estado-en-el-z\%C3\%B3calo-de

La imagen muestra en primer plano un extremo del Zócalo capitalino, sede de los poderes civiles y religiosos del país y de la ciudad de México donde, con letras mayúsculas y EN pintura vinílica, ha sido escrita la frase "FUE El ESTADO". Lo que también sería un tagline está rodeado por una valla de personas que permanecen de pie, vigilantes; protegiéndolo con sus propios cuerpos. Al fondo se observan el Palacio Nacional, el Palacio del Ayuntamiento y la Catedral Metropolitana. La fotografía es del 22 de octubre de 2014 . La pinta monumental fue realizada durante una marcha convocada por los padres de los 43 estudiantes desaparecidos y logró amplificar el sentimiento de indignación de millones de personas que le reclamaban al Estado su responsabilidad en los hechos de Iguala. El emprendimiento fue iniciativa de \#RexisteMX, un colectivo de artistas y activistas gráficos que de manera deliberada seleccionaron esa esquina del Zócalo para escribir la frase sobre las baldosas, de modo que el hecho y sus resultados pudiesen ser captados y transmitidos por una de las webcams de México que permiten una visión total del Zócalo y transmiten en tiempo real a través de internet. A cuatro años de distancia, encontramos que la imagen transmitida por la webcam fue eliminada de los archivos del sitio en internet, pero ha sido reproducida en otras ocasiones en el mismo emplazamiento y muchos otros, dando lugar a nuevos índices de agencia.

"Fue el Estado" condensa, en efecto, el desmentido de la ciudadanía de la versión oficial sobre los hechos de Iguala que primero criminalizó a los estudiantes desaparecidos vinculándolos con el grupo delincuencial Guerreros Unidos y posteriormente, dio a conocer la infame "verdad histórica" del entonces Procurador de la República, Jesús Murillo Karim. Este, el 7 de noviembre del 2014 , ofreció una conferencia de prensa en la que dio a conocer que los 43 estudiantes fueron entregados por la policía municipal de Iguala al grupo de narcotraficantes Los Rojos, quienes tras asesinarlos quemaron sus cuerpos en una gran fogata en el basurero de Cocula y arrojaron sus cenizas en el río San Juan debido a que los confundieron con integrantes de un cártel rival. Así, la frase "Fue el Estado" se convirtió en una consigna que unió a millones de personas logrando modificar la percepción de la ciudadanía sobre la política de seguridad del gobierno conocida como "guerra contra el narcotráfico" ${ }^{3}$ y creó un nexo social en la convicción de que, en el caso de

\footnotetext{
${ }^{3}$ En su primer día de mandato, el 1 de diciembre de 2006, el ex presidente Felipe Calderón declaró en el Auditorio Nacional que la inseguridad era el problema principal del país e informó de las medidas que tomaría: “Una de las tres prioridades que voy a encabezar en mi gobierno es, precisamente, la lucha por recuperar la seguridad pública y la legalidad”. Y agregó: "Sé que restablecer la seguridad no será nada fácil ni rápido, que tomará tiempo, que costará mucho dinero, e incluso y por desgracia, vidas humanas. Pero téngalo por seguro, ésta es una batalla en la que yo estaré al frente, es una batalla que tenemos que librar y que unidos los mexicanos vamos a ganar a la delincuencia" (Felipe Calderón citado en Astorga 2015, p. 21).
} 
Iguala, como en la aludida guerra, las instituciones del Estado y sus representantes mentían al atribuir al crimen organizado la responsabilidad por la escalada de violencia en el país, exonerando, de ese modo, al Ejército mexicano. De acuerdo con Oswaldo Zavala, esa narrativa constituye una matriz discursiva que fue elaborada y diseminada por fuentes estatales para justificar el estado de excepción impuesto por el Estado en vastas regiones del país con el propósito de proteger intereses geopolíticos relacionados con la explotación de recursos naturales. (2018, p. 230) Otros autores también han llamado la atención sobre los enormes beneficios económicos que la "guerra contra las drogas" reporta a diferentes sectores, desde el de la producción y venta de armas en Estados Unidos, el de los empresarios del mercado negro que también trafican con petróleo, hasta la industria bancaria nacional y global.

La imagen captada por la webcam se desplegó en otros índices de agencia, entre ellos la fotografía que aquí se muestra, una tarjeta postal sonora que fue transmitida por radio, y las imágenes captadas por la webcam de la ciudad de México que todavía pueden verse en internet. Además, la intervención en el espacio virtual muestra un desvío del deseo de "ser vistos", de "ese exceso de habitar la red" que Remedios Zafra ha señalado como el centro del domino del sistema red y al cual atribuye la forma en la que nos "entregamos en la red de manera más o menos consciente para nuestra propia dominación." (p. 19)

1. ¿Dónde están?

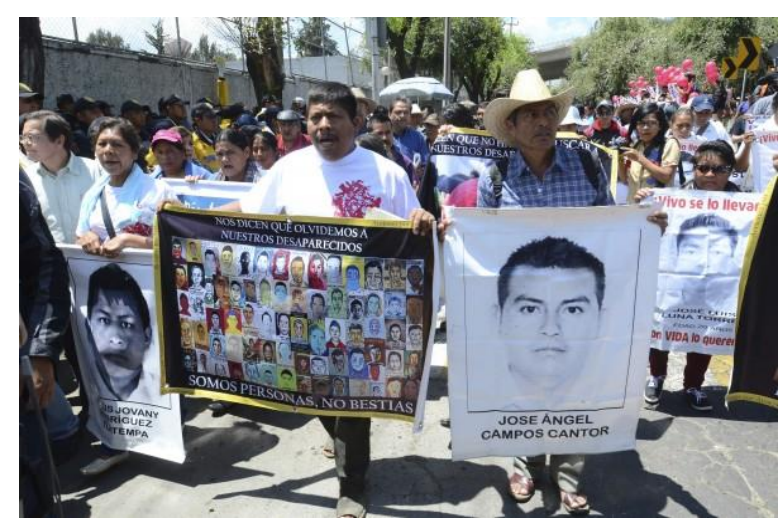

Figura 2. Fotografía de Armando Monroy. Fuente: Cuartooscuro, 9 de abril de 2015. Recuerperado de https://www.proyectodiez.mx/ine-contradice-verdadhistorica-estudiantes-de-ayotzinapa-siguen-desaparecidos/

La fotorgafía registra una marcha celebrada el 8 de abril de 2015 en la ciudad de México, también convocada por los padres de los 43 estudiantes. En primer plano aparecen dos varones que portan imágenes de los rostros de los estudiantes desaparecidos. El de la izquierda porta una imagen de identificación en blanco y negro de uno de ellos, el de la derecha un vinil en el que aparece un colorido mosaico de imágenes realizadas por \#llustradores con Ayotzinapa, la iniciativa creada por la diseñadora Valeria Gallo unos días después de la desaparición forzada de los 43 jóvenes estudiantes a través del hashtag con ese nombre. Las imágenes fueron realizadas por personas de muy diferente profesión y edad que las colocaron en una plataforma en internet a partir de las fotografías publicadas por el gobierno de Guerrero para demandar apoyo a la población para localizar a los estudiantes desaparecidos a través de la publicación de un cartel con sus fotografías de identificación escolar. Desde aquel momento y de manera similar a lo ocurrido en otros países de América Latina y del mundo, las fotografías de los jóvenes desaparecidos han sido utilizadas como instrumento en la lucha política que reclama su presentación con vida y han dado lugar a numerosos índices que han alimentado otros nexos y acciones, tanto en el espacio público como en el virtual, en México y en muchos otros muchos países.

Los participantes del movimiento en demanda de la aparición con vida de los estudiantes de Ayotzinapa comenzaron a hacer uso de la matriz central de lo que podríamos llamar la cultura visual de la desaparición, a saber, el uso de las fotografías de los rostros de las personas desaparecidas como signo de la desaparición forzada y de las luchas políticas por la memoria y la justicia (Langland, 2005, p. 87) que han establecido el rostro como vector principal. (Longoni, 2005) De manera específica \#llustradoresconAyotzinapa fue un emprendimiento que tuvo lugar en el espacio virtual impulsado por el desafío de evocar a las víctimas de la desaparición forzada para infundirles aliento y vida a través de la acción gráfica y, de ese modo, impedir su desaparición de la memoria colectiva (Halwachs, 2004), pero que muy pronto mostró su potencia en el espacio público, donde ha venido funcionando como "batería moral". (Rugillo Cruz, 2017). Efectivamente, las imágenes producidas por los participantes son el otro polo de la política visual del terror con la cual operan por igual el Estado y los grupos criminales comunican su poder a la ciudadanía (Diéguez, 2013), pero también el de la banalidad del expresidente Enrique Peña Nieto y su familia, vinculados a la farándula televisiva (Rugillo Cruz, 2015). Estas imágenes han activado emociones que reinscriben el problema de la violencia en una política visual cuyo núcleo es la afirmación de la responsabilidad con los 
otros como constitutiva de nuestra subjetividad y de nuestra socialidad. (Levinas, 1991). Esa política se basa en el rostro y ubica a la violencia en una dimensión ética fundamental: la de la responsabilidad de hacer vivir al otro. Este aspecto resulta fundamental pues esas imágenes han contribuido también a la reconstitución de una "multitud" en un "nosotros" (Zafra, p. 20) es decir, en una identidad que se forja precisamente en el reconocimiento del otro como aquel que en su existencia y diversidad hace posible mi propio ser. (Bajtin, 2000) En México ese otro son las poblaciones indígenas; el otro definido casi como alteridad radical en razón de color de piel y nivel de clase social.

\section{Son 43 y miles más}

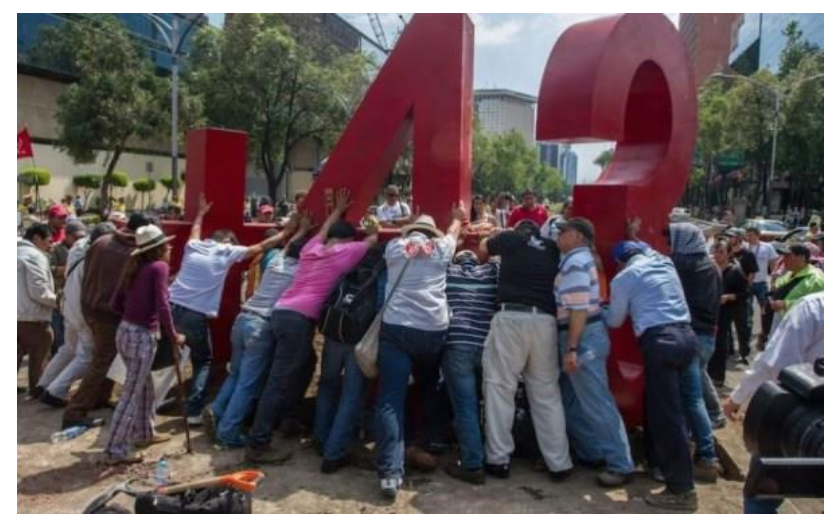

Figura 1. Fuente Esfera Pública. "Antimonumento +43 a los estudiantes de Ayotzinapa". 27 de abril de 2015. Recuperda de: https://esferapublica.org/nfblog/antimonumento-43-a-los-estudiantes-de-ayotzinapa/

Desde los días posteriores al 26 de septiembre del 2014, cuando tuvo lugar la desaparición de los jóvenes normalistas el numeral 43 se convirtió en el significante del reclamo de su aparición con vida y en el símbolo de una movilización social que exige al Estado el castigo a los culpables. Como ha escrito Cristina Híjar González: "Desde un inicio, su sola presentación funcionó como referencia al acontecimiento histórico, no hay necesidad de agregar nada más: se pinta, se imprime, se utiliza como elemento fundamental en el diseño de múltiples materiales, se porta, se grita en un conteo a manera de consigna que culmina con el grito iJusticia i" (2016, p. 11) Así, el 26 de abril del 2015 fue colocado en un camellón de la avenida Reforma de la Ciudad de México una escultura compuesta por el signo + y el numeral 43. A sus pies, en una placa, se grabó la leyenda: "Porque vivos se los llevaron, vivos los queremos". De manera intempestiva y sin permiso de las autoridades gubernamentales, la escultura fue ubicada por los padres de los estudiantes y la Comisión +43 en un punto clave de la memoria espacial de la Ciudad de México: el cruce de Paseo de la Reforma con la avenida Juárez, esto es, el lugar donde la avenida que contiene los monumentos emblemáticos de la memoria oficial del Estado nación mexicano se cruza con la vía que conduce al Zócalo de la Ciudad de México que, como ya mencioné, es sede de la institucionalidad política y religiosa del país y de la ciudad capital.

La imagen a la que me refiero no puede ser más elocuente: muestra a un grupo de personas sosteniendo las piezas de la escultura anti-monumento. Son sus cuerpos los que las sostienen, igual que sostienen el movimiento global por la verdad y la justicia en el caso de los 43 estudiantes y los miles de desaparecidos y asesinados a causa de la "guerra contra el narcotráfico" y de los desaparecidos durante la llamada Guerra Sucia (1969-1982) -un trágico episodio de la historia nacional- que tuvo lugar precisamente en el estado de Guerrero, todos ellos significados con el signo +. La imagen muestra, por tanto, a un grupo de ciudadanos sosteniendo con sus cuerpos la marca del horror en el espacio monumental de la nación mexicana.

La escultura y su ubicación fueron producto de la acción directa de la Comisión +43 -conformada por diseñadores, artistas y antropólogos - que se ha multiplicado también en índices como los performances ${ }^{4}$ que cotidianamente tienen lugar en la pequeña área de cultivo alrededor de la escultura antimonumento +43 y otras acciones que se caracterizan por vincularse estética y políticamente al cuidado de la vida, con lo que afirman su oposición a la necropolítica del régimen. Aquí, igual que en las acciones e imágenes antes referidas, aquí se afirma la importancia material del cuerpo en la configuración de subjetividad.

4 De acuerdo con Diana Taylor los performances funcionan como "actos vitales de transferencia, transmitiendo saber social, memoria y sentido de identidad a través de acciones reiteradas" (Taylor 2011, p. 20). 


\section{CONCLUSIONES}

La producción cultural que ha acompañado la movilización global por Ayotzinapa ha mostrado su capacidad de agencia en la creación de objetos e imágenes que se han multiplicado y diversificado en los espacios público y virtual dando lugar a una polifonía que disuelve la autoría y la distribuye entre la ciudadanía A partir la atribución de responsabilidad del Estado en el caso Igualada, del uso de las imágenes de los rostros de los estudiantes desaparecidos y del numeral 43 se han multiplicado los artefactos o índices de agencia que han logrado crear nuevos nexos de solidaridad y empatía entre las personas y han animado y vivificado la participación ciudadana. Se trata de producciones colectivas de carácter relacional cuyo impacto sobre la emotividad, la capacidad de reflexión y de acción política que ha sostenido la demanda de aparición con vida de los estudiantes y que, igualmente, en su uso ha mostrado las posibilidades del desvío de la producción biopolítica del sistema red hacia la configuración de una identidad que se basa en la inclusión del otro, mostrando, de esa manera, que lo que somos se modifica individual y socioculturalmente. De tal suerte, esas producciones lograron transformar la percepción sobre la crisis política, social y humanitaria en la que se encuentra el país desde el 2006 que condujo a cambio de régimen el psado 1 de julio de 2018.

\section{FUENTES REFERENCIALES}

Astorga, L. (2015). “¿Qué querían que hiciera?” Inseguridad y delincuencia organizada en el gobierno de Felipe Calderón. México: Grijalbo.

Bajtín, M. (2000). Yo también soy (Fragmentos sobre el otro). Madrid: Taurus.

Diéguez, I. (2013). Cuerpos sin duelo. Iconografías y teatralidades del dolor. Córdoba: Ediciones DocumentA/Escénica.

Galán Castro, E. (2017). Espiritualidad, identidad y acción colectiva en el Movimiento por la Paz con Justicia y Dignidad. El Cotidiano, núm. 206 (noviembre-diciembre), 19-31.

Gell, A. (2016). Arte y Agencia. Una teoría antropológica. Buenos Aires: Katz.

Halbwachs, M. 2004. Los marcos sociales de la memoria. Barcelona: Anthropos.

Híjar González, C. (2016). El retrato y el numeral 43: artefactos político-estéticos en la acción colectiva por Ayotzinapa en México. Tesis para obtener el grado de Maestra en Comunicación y Política. Universidad Autónoma Metropolitana

Illades, E. (2015). La noche más triste. La desaparición de los 43 estudiantes de Ayotzinapa. México: Grijalbo. Unidad Xochimilco, México.

Langland, V. (2005). Fotografía y memoria. En Escrituras, imágenes y escenarios ante la represión (pp. 87-90), compilado por E. Jelin y A. Longoni. Madrid: Siglo XXI Editores.

Levinas, E. (1991). Ética e infinito. Madrid: Visor.

Longoni, A. 2010. Fotos y siluetas: dos estrategias contrastantes en la representación de los desaparecidos. En Los desaparecidos en la Argentina. Memorias, representaciones e ideas (1983-2008) (pp. 43-63), coordinado por E. Crenzel. Buenos Aires: Biblos.

Reguillo Cruz, R. (2015). La turbulencia en el paisaje: de jóvenes, necropolítica y 43 esperanzas. En Juvenicidio. Ayotzinapa y las vidas precarias en América Latina y España (pp. 59-78), coordinado por J. M. Valenzuela. Barcelona/Guadalajara/Tijuana: NED/ITESO/EI Colegio de la Frontera Norte.

Reguillo Cruz, R. (2017). Paisajes insurrectos. Jóvenes, redes y revueltas en el otoño civilizatorio. Barcelona: Nuevos Emprendimientos Editoriales.

Taylor, D. (2015). El archivo y el repertorio. El cuerpo y la memoria cultural en las Américas. Santiago de Chile: Ediciones Universidad Alberto Hurtado.

Zafra, R. (2015). Ojos y capital. Bilbao: connsoni.

Zavala, O. 2018. Los cárteles no existen. Narcotráfico y cultura en México. Barcelona: Malpaso ediciones. 